\title{
A psychometric investigation of Brazilian Portuguese versions of the Caregiver Eating Messages Scale and Intuitive Eating Scale-2
}

\author{
Wanderson Roberto da Silva ${ }^{1}$. Angela Nogueira Neves ${ }^{2} \cdot$ Lucilene Ferreira $^{3}$. \\ Juliana Alvares Duarte Bonini Campos ${ }^{1} \cdot$ Viren Swami ${ }^{4,5}$
}

Received: 16 February 2018 / Accepted: 27 July 2018

(c) Springer Nature Switzerland AG 2018

\begin{abstract}
The Caregiver Eating Messages Scale (CEMS) was developed to assess perceived restrictive or critical caregiver messages in relation to food intake and pressure to eat, whereas the Intuitive Eating Scale-2 (IES-2) measures one's tendency to follow internal cues of hunger and satiety when making eating-related decisions. Both scales are useful in the arsenal of eating behaviour scholars. Here, we developed Brazilian Portuguese translations of both scales and assessed their psychometric properties in Brazilian adults. A total of 288 participants $(\mathrm{men}=52.8 \%)$ completed the CEMS, IES-2, Body Appreciation Scale (BAS), and a demographic questionnaire. The results of confirmatory factor analysis indicated that the factor structure of both scales had adequate fit following the elimination of items and addition of covariances. Evidence of adequate factorial, convergent and discriminant validity, as well as reliability was identified. Furthermore, correlations of CEMS and IES-2 with BAS scores and body mass index were obtained. Both instruments' models were found to be invariant across sex, with men having significantly higher scores on three subscales of the IES-2 only. These results provide evidence for the psychometric properties of the CEMS and IES-2 in Brazilian Portuguese-speaking adults.
\end{abstract}

Level of Evidence: V, cross-sectional descriptive study.

Keywords Caregiver eating messages $\cdot$ Intuitive eating $\cdot$ Eating behaviour $\cdot$ Body appreciation

Wanderson Roberto da Silva

wandersonroberto22@gmail.com

Angela Nogueira Neves

angela.esefex@yahoo.com.br

Lucilene Ferreira

luci_ferreira2003@yahoo.com.br

Juliana Alvares Duarte Bonini Campos

jucampos@fcfar.unesp.br

Viren Swami

viren.swami@anglia.ac.uk

1 Department of Food and Nutrition, School of Pharmaceutical Sciences, São Paulo State University (UNESP, Campus Araraquara), Araraquara-Jau Road Km1, Araraquara, SP 14800-903, Brazil

2 Physical Education School of Brazilian Army, Rio de Janeiro, Brazil

3 Department of Health Sciences, University of Sagrado Coração, Bauru, Brazil

4 Department of Psychology, Anglia Ruskin University, Cambridge, UK

5 Centre for Psychological Medicine, Perdana University, Serdang, Malaysia

\section{Introduction}

Evidence of an association between dietary factors and noncommunicable diseases is very well-established [1]. More specifically, a large body of evidence indicates that healthy eating can help to reduce the risk of chronic diseases [2]. Unfortunately, however, the proportion of populations meeting healthy eating recommendations remains small [3], particularly in low- and middle-income countries [4]. Thus, the eating decisions of individuals are important aspects that should be considered, as they are among the most frequent of daily human behaviours [5] and are strongly shaped by the social context [6]. For instance, the family environment is known to play an important role in shaping the eating decisions of children. Much less research has focused on the impact of caregiver eating messages beyond adolescence [7], partly because until recently appropriate measurement tools with which to measure perceived caregiver eating messages were not available. This was rectified with the development of the Caregiver Eating Messages Scale (CEMS) [8]. 
Kroon van Diest and Tylka [8] developed the items of CEMS to measure perceived caregiver eating messages. Based on exploratory factor analysis, two factors were extracted measuring restrictive/critical messages (RCM) and pressure-to-eat messages (PEM). An adequate fit of this two-dimensional model was further found in two US college samples of women and men [8]. To our knowledge, however, the factor structure of the CEMS has not been investigated outside the US and in non-English-speaking samples.

Beyond caregiver eating messages, some scholars have also looked at the role of intra-individual differences in intuitive eating. Intuitive eating generally refers to a tendency to respond to physiological hunger and satiety signals, rather than external cues such as emotional fluctuation or distress $[7,9]$. Although various measures of intuitive eating exist in the literature, the Intuitive Eating Scale-2 (IES-2) is the most prominent [10]. The IES-2 is a measure that was designed to evaluate an individual's tendency to follow physiological signs of hunger and satiety considering Unconditional Permission to Eat (UPE), Eating for Physical Rather than Emotional Reasons (EPRER), Reliance on Hunger and Satiety Cues (RHSC), and Body-Food Choice Congruence (BFCC). In addition, IES-2 scores were reported to have adequate internal consistency and good test-retest reliability over a 3-week period in US women and men, but to our knowledge no study has evaluated IES-2 in the Brazilian context.

As a contribution to the available literature, the present study examined the psychometric properties of novel Brazilian Portuguese translations of the CEMS and IES-2. In the first instance, the CEMS has not previously been translated into Brazilian Portuguese; conversely, while a European Portuguese translation of the IES-2 is available [20], it should be noted that, while European and Brazilian Portuguese are considered two dialects of the same language, there are linguistic variations in lexicon, phonology, and grammar [11]. These issues mean that novel translations of both measures into Brazilian Portuguese are required. More broadly, the present work is an important step for research because studies indicate that antecedents of healthy eating, such as caregiver eating messages and intuitive eating, vary across cultural contexts [12-14]. More specifically, Brazil offers a useful setting in which to examine the factor structure of the CEMS and IES-2 for a number of reasons.

First, Brazilians may have different eating patterns and habits compared to that of other national groups. Food, and the celebration of food, occupies a central role in the lives of many Brazilians, particularly women, because of its relationship with social composition, such as that between family members [15]. Second, Brazil has undergone a nutrition transition that has resulted in important shifts in eating habits (the availability of natural foods has decreased whereas the availability of processed foods has increased) [16]. This has resulted in a substantial increase in rates of obesity across all social classes in the past several decades [17]. One helpful step would, therefore, come through the provision of validated tools for assessing attitudes towards healthy eating in this context [18]. For these reasons, we initially translated the CEMS and IES-2 into Brazilian Portuguese and investigated their factor structures using confirmatory factor analysis. Doing so is vital because it would provide scholars with appropriate tools to better understand the nature, antecedents, and outcomes of eating behaviours in Brazilian populations.

\section{Methods}

\section{Design}

This study used a cross-sectional design with a non-probabilistic convenience sampling technique. The sampling size was calculated using Hair, Black, Badin, and Anderson's [19] recommendation that sample size should meet a ratio of five to ten $(k)$ participants per items of instrument. Considering that IES-2 is the longer of the two scales analysed here (23 items), we used it as the basis for our sampling calculation. Thus, the minimum sample should meet a ratio of 115-230 individuals. In addition, because we wished to examine sex differences, the minimum sample size was considered per sub-group (women and men).

\section{Participants}

Participants provided their sex, age, weight, and height (to calculate the body mass index-BMI), ethnicity, and highest educational qualifications. The final sample consisted of 288 individuals ( $n=152$ for women; $n=136$ for men) recruited from the community in the state of São Paulo, Brazil. Participants ranged in age from 18 to 40 years $(24.01 \pm 5.91$ for total sample; $23.97 \pm 6.10$ for women; $24.04 \pm 5.74$ for men) and in self-reported BMI from 18.87 to $38.42 \mathrm{~kg} / \mathrm{m}^{2}$ $(24.17 \pm 3.52$ for total sample; $23.29 \pm 3.29$ for women; $24.96 \pm 3.54$ for men). In the total sample, $85.7 \%$ of participants described themselves as white, $5.9 \%$ as multiracial, $4.2 \%$ as black, and $4.2 \%$ as of some other ancestry. In terms of educational qualifications, $2.8 \%$ had a school certificate, $28.0 \%$ had completed secondary schooling, $61.2 \%$ had an undergraduate degree, and $8.0 \%$ had a graduate degree.

\section{Measures}

\section{Caregiver Eating Messages Scale (CEMS)}

The CEMS was proposed by Kroon van Diest and Tylka [8] as a 10-item measure of perceived restrictive or critical caregiver messages in relation to food intake and pressure to 
eat. In US college samples, the authors reported that scores on the scale had a two-dimensional factor structure, consisting of RCM (items 5, 6, 7, 8, and 10) and PEM (items 1, 2, 3, 4 , and 9). All items were rated on a 5 -point scale $(1=$ Never, $5=$ Always), with higher scores indicating greater perceived pressure to eat or criticalness/restriction of food choice or intake.

\section{Intuitive Eating Scale 2 (IES-2)}

The IES-2 was proposed by Tylka and Kroon van Diest [10] as a 23-item measure designed to evaluate an individual's tendency to follow physiological signs of hunger and satiety to choose what, when, and how much to eat. Seven items are reverse-coded and, in US adults, the authors reported a four-factor structure with item distribution as follows: (1) UPE (items 1, 3, 4, 9, 16, and 17); (2) EPRER (items 2, 5, 10, 11, 12, 13, 14, and 15); (3) RHSC (items 6, 7, 8, 21, 22, and 23); and (4) BFCC (items 18, 19, and 20). The structural model also has a second-order factor, named Intuitive Eating (IE). All items were rated on a 5 -point scale $(1=$ Never, $5=$ Always). Higher scores indicate a greater reliance on physiological hunger and internal cues of hunger and satiety.

\section{Body Appreciation Scale (BAS)}

The BAS was proposed by Avalos et al. [20] as a 13-item measure of positive body image that has been found to have a one-dimensional factor structure in US college samples [20]. However, Swami et al. [21] showed scores on a Brazilian Portuguese version of BAS reduced to two dimensions, with only one subscale (10 items) measuring general body appreciation. This finding is consistent with other studies showing that BAS scores have a two-factor structure in some samples [22]. More recently, Ferreira et al. [23] reported that a two-dimensional model with eight items of BAS scores had better fit than all other tested models; these authors drew a distinction between "Body Valorisation" (BV; the construct most sclosely related to body appreciation, items $=3,4,5$, and 10) and "Body Care" (BC; more akin to body image investment, items $=1,6,7$, and 11). The present data showed acceptable fit with this two-dimensional model of BAS. The items of BAS were rated on a 5-point scale $(1=$ Never, $5=$ Always $)$, with higher scores reflecting higher body valorisation or body care.

\section{Development of Brazilian Portuguese translations}

Brazilian Portuguese translations of the CEMS and IES-2 were prepared according to the Institute for Work and Health's five-step (translation, synthesis, back-translation, experts committee, and pre-test) guidelines for the crosscultural adaptation of self-report measures [24]. First, two translations $\left(T_{1}\right.$ and $\left.T_{2}\right)$ were made independently by different native Brazilian speakers, proficient in English. Next, a synthesis version $\left(\mathrm{T}_{12}\right)$ of each scale was drawn up by the two translators and a neutral judge, reflecting on the consensus between $T_{1}$ and $T_{2}$. In sequence, $T_{12}$ of each scale were sent to two back-translators (native English speakers with Brazilian Portuguese proficiency), who worked independently and without knowledge of the original scale. In the fourth step, all produced material (T1, T2, $\mathrm{T} 12, \mathrm{BT} 1, \mathrm{BT} 2$ ) and the original scale were forwarded to an experts' committee consisting of a methodologist, a linguist, a body image specialist, a nutritionist, and the previous translators, back-translators, and the synthesis judge. This committee examined the versions of each questionnaire and discussed the items to ensure a clear pre-test version, equivalent to the original in terms of semantics, idiomatic, culture, and concept [25]. The expert committee discussed all items, instructions, and responses alternatives, resulting in pre-test versions of the IES-2 and CEMS. The fifth step, pre-test, showed no particular difficulties with the IES-2, but of the ten recruited pre-test participants, $80 \%$ showed difficulties in responding to the CEM's original 6-point scale (because of the absence of a neutral response). For this reason, we altered the response scale of the CEM so as to use a 5-point scale, with the anchors unaltered. A second pre-test with a new set of ten participants $(50 \%$ men) was conducted; the revised response scale of the CEMS presented no difficulties for participants. The cross-cultural adapted Brazilian Portuguese version of the CEMS and IES-2 are presented in Table 1.

\section{Procedures}

Three researchers trained in psychological research methods recruited participants opportunistically from various sites of congregate activities, such as on-campus locations, shopping mall food courts, and fashion stores. Potential participants were invited to take part in a study ostensibly on health and well-being and completed an informed consent form prior to participation. All participants completed paper-and-pencil versions of the questionnaire in a specific location reserved for the research. The order of measures was counterbalanced for each participant. Upon completion and return of the questionnaire, participants were provided with a debrief sheet that included contact details of the research team. Participation in the study was voluntary and limited to respondents aged 18 years and above. Participants did not receive any form of remuneration. Ethics approval was obtained from Human Research Ethics Committee of University of Campinas, in São Paulo, Brazil (C.A.A.E.08009212.9.0000.5404). 
Table 1 English and Portuguese version of Caregiver Eating Messages Scale (CEMS) and Intuitive Eating Scale 2 (IES-2)

\begin{tabular}{ll}
\hline Item English version & Portuguese version
\end{tabular}

\section{CEMS}

1 Told you to eat all the food on your plate

2 Made sure you finished all the food that was on your plate

3 Made you eat at times you weren't hungry

4 Told you to eat all your vegetables after you told them you didn't want to eat any more

5 Looked at you with raised eyebrows at how much you were eating, making you feel that you were eating too much

6 Commented that you were eating too much

7 Made fun of you (or scolded you) for eating too much

8 Told you that you shouldn't eat certain foods because they will "make you fat"

9 Made you eat despite the fact that you were full

10 Talked about dieting or restricting certain high calorie foods IES-2

$1^{\text {a }}$ I try to avoid certain foods high in fat, carbohydrates, or calories

$2^{\mathrm{a}} \quad$ I find myself eating when I'm feeling emotional (e.g., anxious, depressed, sad), even when I'm not physically hungry

3 If I am craving a certain food, I allow myself to have it

$4^{\mathrm{a}} \quad$ I get mad at myself for eating something unhealthy

$5^{\mathrm{a}} \quad$ I find myself eating when I am lonely. even when I am not physically hungry

$6 \quad$ I trust my body to tell me when to eat

7 I trust my body to tell me what to eat

8 I trust my body to tell me how much to eat

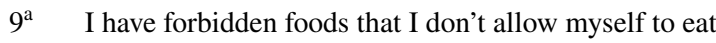

$10^{\mathrm{a}}$ I use food to help me soothe my negative emotions

$11^{\mathrm{a}}$ I find myself eating when I am stressed out, even when I am not physically hungry

12 I am able to cope with my negative emotions (e.g., anxiety, sadness) without turning to food for comfort

13 When I am bored, I do NOT eat just for something to do

14 When I am lonely, I do NOT turn to food for comfort

15 I find other ways to cope with stress and anxiety than by eating

16 I allow myself to eat what food I desire at the moment

17 I do NOT follow eating rules or dieting plans that dictate what, when and/or how much to eat

18 Most of the time, I desire to eat nutritious foods

19 I mostly eat foods that make my body perform efficiently (well)

20 I mostly eat foods that give my body energy and stamina

21 I rely on my hunger to tell me when to eat

22 I rely on my fullness (satiety) signals to tell me when to stop eating

23 I trust my body to tell me when to stop eating
Disseram para você comer toda a comida que estava no seu prato

Conferiram se você havia comido tudo que estava no seu prato

Fizeram você comer mesmo sem fome

Disseram para você comer todos os seus legumes mesmo depois de você dizer que já não queria comer mais

Olharam com repreensão para o quanto você estava comendo, fazendo com que você sentisse que estava comendo demais

Comentaram que você estava comendo muito

Fizeram piadas (ou te deram uma bronca) por você comer demais

Disseram que você não deveria comer certos tipos de comidas porque elas iam te deixar gordo(a)

Fizeram você comer mesmo você já estando satisfeito

Falaram sobre dietas ou sobre evitar comidas calóricas

Eu tento evitar comidas ricas em gordura, carboidratos ou calorias

Eu como quando estou emotivo(a) (por exemplo: ansioso(a), deprimido(a), triste), mesmo não estando com fome

Se eu estiver com vontade de comer um certo tipo de comida, eu me permito comer

Eu fico triste comigo mesmo(a) se como algo que não é saudável

Eu como quando me sinto sozinho(a), mesmo não estando com fome

Eu confio no meu corpo para me dizer quando comer

Eu confio no meu corpo para me dizer o que comer

Eu confio no meu corpo para me dizer o quanto comer

Eu tenho "comidas proibidas" que não me permito comer

Eu uso a comida para me ajudar a aliviar minhas emoções negativas

Eu como quando estou estressado(a), mesmo não estando com fome

Eu consigo lidar com minhas emoções negativas (ansiedade, tristeza) sem ter que usar a comida como uma forma de conforto

Quando eu estou entediado(a), eu NÃO como alguma coisa só por comer

Quando me sinto sozinho(a), eu NÃO uso a comida como uma forma de conforto

Eu descobri outras formas, diferentes de comer, para lidar com o estresse e a ansiedade

Eu me permito comer a comida que eu tenho vontade naquele momento

Eu NÃO sigo dietas ou regras que definem o que, onde e o quanto eu devo comer

Na maioria das vezes, eu tenho vontade de comer comidas nutritivas

Principalmente, eu como alimentos que ajudam meu corpo a funcionar bem

Principalmente, eu como alimentos que dão disposição e energia para meu corpo

Eu confio na minha fome para me dizer quando comer

Eu confio na minha sensação de saciedade para me dizer quando devo parar de comer

Eu confio no meu corpo para me dizer quando devo parar de comer

${ }^{\text {a }}$ Reverse items 


\section{Data analysis}

All analyses were carried out using MPLUS (version 7.11). The psychometric properties of the original models of the CEMS and IES-2 were evaluated first with the total sample and subsequently with women and men separately. Construct validity was examined through factorial, convergent, and discriminant validity. Factorial validity was assessed by confirmatory factor analysis using the Unweighted Least Squares estimator with mean and variance adjusted (ULSMV). We used the fit indices of Chi square by degrees of freedom ratio $\left(\chi^{2} / d f\right)$, the comparative fit index (CFI), the Tucker-Lewis index (TLI), and the root mean square error of approximation (RMSEA) with confidence interval of $90 \%$ to assess the models. According to Marôco [26], a model can be considered to have acceptable fit when $\chi^{2} / d f<5.00$, CFI and TLI $>0.90$, and RMSEA $<0.10$. Moreover, the factorial weight $(\lambda)$ of each item was assessed and values $\geq 0.45$ were considered adequate. We calculated the modification indices using the Lagrange Multipliers (LM) method to improve model fit for values $>11$ [26]. To assess convergent validity, we calculated the average variance extracted (AVE) for each factor of the scales [27]. Values of AVE $\geq 0.50$ were considered adequate [26]. Discriminant validity was evaluated using the squared correlation $\left(r^{2}\right)$ among factors and values of AVEs [27]. When the AVE values for each pair of correlated factors were $\geq r^{2}$, the discriminant validity among factors was considered adequate.

The factorial invariance of instruments (CEMS and IES2 ) in women and men also was assessed. The invariance test was performed by multigroup analysis using the Chi square difference $\left(\Delta \chi^{2}\right)$ between the model with free factorial weights and the model with equal weights fitted to sample. To assess the invariance in sexes, the total sample were divided into two subgroups (women: $n=152$, men: $n=136$ ) and the test was performed considering analysis of factorial weights $(\lambda)$, intercepts $(I)$, and residues' variance/ covariance (cov/res). Support for metric (weak) invariance was supported if $p \Delta \chi^{2}{ }_{\lambda}$ was $>0.05$. Metric and scalar (moderate) invariance was found if $p \Delta \chi_{\lambda}^{2}$ and $p \Delta \chi^{2}{ }_{I}$ were $>0.05$. Finally, metric, scalar, and strict (strong) invariance was supported if $p \Delta \chi_{\lambda}^{2}, p \Delta \chi^{2}{ }_{l}$, and $p \Delta \chi^{2}{ }_{\text {cov/res }}$ were $>0.05[26,28]$.

The reliability of each scale was also evaluated. Internal consistency $(\alpha)$ and composite reliability (CR) were calculated for each factor of the scales. To calculate the CR we used the recommendations of Fornell and Larcker [27]. Values for $\alpha$ and CR above 0.70 indicated adequate reliability [26].

To test the nomological hypothesis regarding the relationship of BAS scores and BMI values with the CEMS and IES scores factors, we computed bivariate correlations between the variables for each sex. Finally, we computed a series of independent-samples $t$ tests to examine sex differences in RCM, PEM, UPE, EPRER, RHSC, and BFCC scores.

\section{Results}

\section{Factor structure}

Table 2 reports the indices used to assess the fit of the CEMS and IES-2 models in our data. Neither parent model presented satisfactory fit on the first run of data. For the CEMS with the total sample, one error covariance was added between items one and two, with both items from the PEM factor, and the elimination of item ten, due to high residuals. Following this change, the model achieved satisfactory fit in both subsamples (see Table 2). In the case of the IES-2, items 1,13 , and 15 consistently showed poor factors loading and the item four showed high residuals, therefore, these items were excluded. With regards to second-order factor, this structure did not achieve a fit in our sample and therefore, we kept the structure with four first-order factors. Following these changes, the IES-2 showed adequate fit in the total sample, as well as for women and men (see Table 2).

\section{Convergent validity}

Evidence of convergent and discriminant validity is reported in Tables 2 and 3. In the CEMS, there was lack of convergent validity of PEM factor only in the female sample, but the value is at the limit of significance $(\mathrm{VEM}=0.48)$. With regards to the IES-2, after fit of model all samples showed adequate convergent validity. With regards to $r^{2}$ values, scores on both scales showed good indicators for all samples indicating adequate discriminant validity of all factors of both scales.

\section{Reliability}

Table 2 shows the parameters ( $\alpha$ and CR) used to evaluate the reliability of the instruments. In both scales, all factors showed adequate values of $\alpha$ and CR.

\section{Factorial invariance}

The invariance test between women and men supported metric, scalar, and strict invariance (strong) for the CEMS, $\Delta \chi^{2}{ }_{\lambda}(7)=12.971, p=0.073 ; \Delta \chi^{2}{ }_{I}(32)=44.599$, $p=0.069 ; \Delta \chi_{\text {cov/res }}^{2}(25)=32.952, p=0.132$. In the case of IES-2, only metric invariance (weak) was found, $\Delta \chi_{\lambda}^{2}(15)=18.858, p=0.220 ; \Delta \chi_{I}^{2}(68)=109.358, p=0.001$; $\Delta \chi_{\text {cov/res }}^{2}(53)=95.025, p<0.001$. 


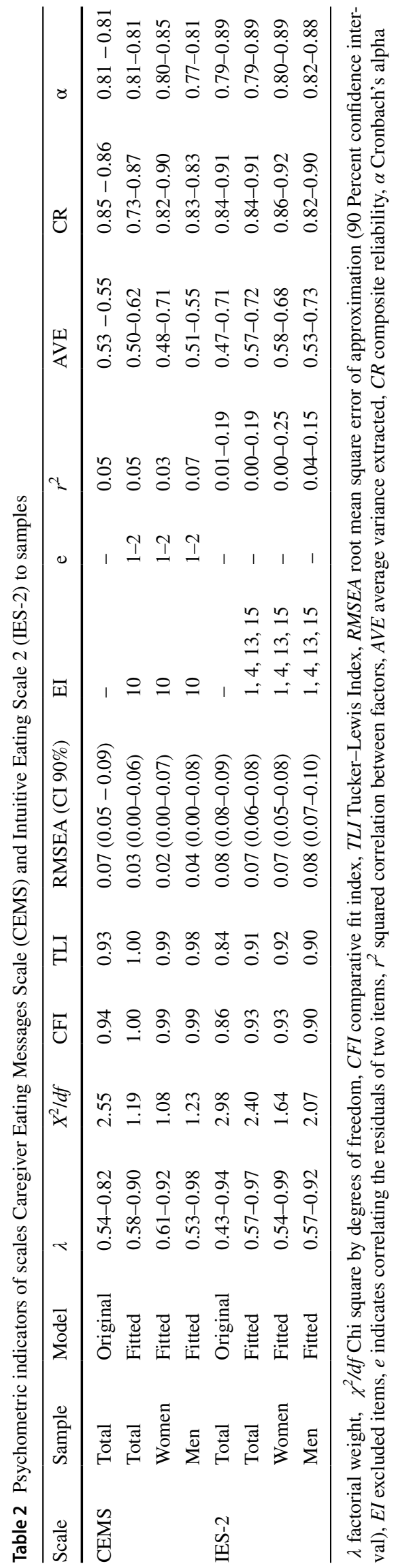

\section{Further analyses}

Regarding nomological validity, we calculated the correlations between PEM, RCM, UPE, EPRER, RHSC, BFCC, $\mathrm{BV}, \mathrm{BC}$ factors (using the fitted models), and BMI by sex (see Table 4).

For the female sample, RCM was negatively correlated with EPRER, BV and BC positively correlated with BMI; UPE had a positive correlation with BV; EPRER and RHSC had positive correlations with BV and BC. RHSC had negative correlation with BMI; BFCC was positively correlated with $\mathrm{BC}$; $\mathrm{BFCC}, \mathrm{BV}$ and $\mathrm{BC}$ had negative correlations with $\mathrm{BMI}$. For the male sample, RCM was negatively correlated with RHSC, BV and positively with BMI and PEM; BV had positive correlations with EPRER, RHSC and BFCC. $\mathrm{BC}$ had a negative correlation with UPE and positive correlations with EPRER, RHSC and BFCC. BMI had negative correlations with RHSC, BV and BC.

We also examined sex differences in RCM, PEM, UPE, EPRER, RHSC, and BFCC scores (see Table 5). The results for the CEMS indicated that there were no significant sex differences on both RCM and PEM scores. In the case of IES-2, results indicated significant sex differences on EPRER, RHSC and BFCC scores.

\section{Discussion}

This study translated and adapted the CEMS and IES-2 into Brazilian Portuguese and examined their psychometric properties in samples of Brazilian Portuguese-speaking adults. Our results suggested that some modifications were required to attain adequate fit of scales, although these modifications did not compromise the theoretical structure proposed originally. Furthermore, we observed that the fitted models of both scales were invariant across sex, suggesting that these instruments may be useful for assessing eating behaviour in both women and men.

Concerning the factorial validity of the CEMS, our results showed that the structural model of two factors (restrictive/ critical messages and pressure-to-eat messages) matched the structural model reported in the original study by Kroon van Diest and Tylka [8]. On the other hand, the elimination of one item (Item \#10) was undertaken due to high residuals found among this item and other items. In addition, we allowed for a correlation between two items because they had similar theoretical content (Items \#1 and Item \#2) and are allocated to the same factor. Following these modifications, the indices of factorial and discriminant validity and reliability of CEMS were adequate in our sample. It is worth commenting on our decision to accept the covariance errors between items for a better fit of CEMS. Common causes for this include item redundancy (caused by similar content 
Table 3 Values of average variance extracted, correlation and shared variance among factors of Intuitive Eating Scale 2 (IES-2) for samples

\begin{tabular}{lllll}
\hline IES-2 factor & UPE & EPRER & RHSC & BFCC \\
\hline UPE & $\mathbf{0 . 5 7 , \mathbf { 0 . 6 4 } , \mathbf { 0 . 5 3 }}$ & $0.05^{*},-0.01^{*}, 0.23$ & $0.30,0.36,0.30$ & $-0.36,-0.30,-0.39$ \\
EPRER & $0.00^{*}, 0.00^{*}, 0.05$ & $\mathbf{0 . 5 0 , 0 . 6 0 , 0 . 5 6}$ & $0.44,0.50,0.32$ & $0.38,0.29,0.32$ \\
RHSC & $0.09,0.13,0.09$ & $0.19,0.25,0.10$ & $\mathbf{0 . 6 3 , 0 . 6 5 , 0 . 6 1}$ & $0.24 .0 .21,0.21$ \\
BFCC & $0.13,0.09,0.15$ & $0.14,0.08,0.10$ & $0.04,0.04,0.04$ & $\mathbf{0 . 7 2 , 0 . 6 8 , 0 . 7 3}$ \\
\hline
\end{tabular}

UPE unconditional permission to eat, EPRER eating for physical rather than emotional reasons, $R H S C$ reliance on hunger and satiety cues, $B F C C$ body-food choice congruence. Sequence of values: First $=$ total sample, Second $=$ female sample, Third $=$ male sample. The values of average variance extract are in the diagonal line, on bold (fitted models). Below the bold diagonal, are the values of the shared variance of each pair of factors. Above the bold diagonal, are the correlations between each factor

*Non-significant correlations

Table 4 Correlation matrix among the factors' scores of Caregiver Eating Messages Scale (CEMS), Intuitive Eating Scale 2 (IES-2), Body Appreciation Scale (BAS), and Body Massa Index (BMI)

\begin{tabular}{llllllllll}
\hline & CEMS_PEM & CEMS_RCM & IES2_UPE & IES2_EPRER & IES2_RHSC & IES2_BFCC & BAS_BV & BAS_BC & BMI \\
\hline CEMS_PEM & 1 & 0.122 & 0.042 & -0.062 & -0.012 & -0.028 & -0.006 & 0.004 & 0.059 \\
CEMS_RCM & $0.175^{*}$ & 1 & -0.079 & $-0.327^{* *}$ & -0.164 & -0.137 & $-0.361^{* *}$ & $-0.324^{* *}$ & $0.348^{* *}$ \\
IES2_UPE & -0.061 & -0.156 & 1 & 0.003 & $0.263^{* *}$ & $-0.252^{* *}$ & $0.411^{* *}$ & -0.005 & -0.110 \\
IES2_EPRER & 0.101 & -0.089 & 0.118 & 1 & $0.426^{* *}$ & $0.192^{*}$ & $0.357^{* *}$ & $0.314^{* *}$ & -0.156 \\
IES2_RHSC & -0.114 & $-0.245^{* *}$ & $0.195^{*}$ & $0.258^{* *}$ & 1 & 0.150 & $0.542^{*}$ & $0.359^{* *}$ & $-0.240^{* *}$ \\
IES2_BFCC & 0.056 & 0.032 & $-0.346^{* *}$ & $0.239^{* *}$ & $0.182^{*}$ & 1 & 0.156 & $0.354^{* *}$ & $-0.218^{*}$ \\
BAS_BV & -0.044 & $-0.259^{* *}$ & 0.131 & $0.247^{* *}$ & $0.466^{* *}$ & $0.255^{* *}$ & 1 & $0.621^{* *}$ & $-0.403^{* *}$ \\
BAS_BC & 0.010 & -0.126 & $-0.216^{* *}$ & $0.286^{* *}$ & $0.384^{* *}$ & $0.522^{* *}$ & $0.605^{*}$ & 1 & $-0.421^{* *}$ \\
BMI & -0.079 & $0.258^{* *}$ & -0.030 & -0.104 & $-0.274^{* *}$ & 0.004 & $-0.301^{*}$ & $-0.221^{* *}$ & 1 \\
\hline
\end{tabular}

Factors of CEMS: PEM pressure-to-eat messages, RCM restrictive/critical messages. Factors of IES2: UPE unconditional permission to eat, EPRER eating for physical rather than emotional reasons, $R H S C$ reliance on hunger and satiety cues, $B F C C$ body-food choice congruence. Factors of BAS: $B V$ body valorisation, $B C$ body care. Above the diagonal are the correlations for the female sample. Below the diagonal, are the correlations for the male sample. $* p<0.05, * * p<0.01$

Table 5 Relationship of factors' scores of Caregiver Eating Messages Scale (CEMS) and of Intuitive Eating Scale 2 (IES-2) among women and men

\begin{tabular}{lllrrr}
\hline & Women $(M \pm \mathrm{SD})$ & Men $(M \pm \mathrm{SD})$ & \multicolumn{1}{c}{$d$} & \multicolumn{1}{c}{$d$} \\
\hline CEMS_PEM & $2.69 \pm 0.86$ & $2.82 \pm 0.86$ & 1.32 & 0.13 & 0.189 \\
CEMS_RCM & $1.97 \pm 0.96$ & $2.07 \pm 0.91$ & 0.86 & 0.09 & 0.390 \\
IES2_UPE & $3.93 \pm 0.84$ & $3.73 \pm 0.90$ & -1.92 & -0.20 & 0.056 \\
IES2_EPRER & $3.08 \pm 0.93$ & $3.87 \pm 0.82$ & 7.74 & 0.80 & $<0.001^{*}$ \\
IES2_RHSC & $3.28 \pm 0.83$ & $3.53 \pm 0.83$ & 2.47 & 0.24 & $0.014^{*}$ \\
IES2_BFCC & $3.39 \pm 0.80$ & $3.76 \pm 0.84$ & 3.79 & 0.37 & $<0.001$ \\
\hline
\end{tabular}

Factors of CEMS: PEM pressure-to-eat messages, $R C M$ restrictive/critical messages. Factors of IES2: UPE unconditional permission to eat, EPRER eating for physical rather than emotional reasons, $R H S C$ reliance on hunger and satiety cues, $B F C C$ body-food choice congruence. $M$ mean, $S D$ standard deviation, $t t$ test, $d$ mean difference. $* p<0.05$ or social desirability) and/or an omission of an exogenous factor [29]. The acceptance of covariance error should have theoretical support, rather than a purely statistical reason. It is unlikely that social desirability is a factor for error covariance, since we ensured conditions for data collection to reduce this bias (voluntary and anonymous participation). It is also unlikely that an ignored latent variable (factor) was missing in the three scales, since the analysed models were, on the one hand, already proposed and investigated by previously studies and, on the other, based on qualitative and qualitative eating behaviour research. It is, therefore, possible that the existence of error covariance was due to similar content between items, as found in previous Brazilian Portuguese psychometric studies [21,30] which does not decrease their importance on the scale nor of the quality of the statistical analysis.

We also found a significant negative correlation between RCM scores and BV scores, in both women and men. 
Broadly speaking, these results are consistent with the findings of Kroon van Diest and Tylka [8] and provide evidence for the validity of the RCM factor. It would, therefore, appear that restrictive/critical caregiver eating messages is associated with lower body appreciation in both women and men in Brazil, although there may be unique mediating factors (e.g., body acceptance by others; internalization of media ideals) that we did not measure in the present work. In addition, we found significant correlations between RCM scores and BMI in both women and men, which is also consistent with the results of Kroon van Diest and Tylka [8]. Restrictive/critical messages may encourage eating in the absence of hunger, which is consistent with findings among adolescents [31].

With regards to IES-2, some changes were also permitted to attain good fit in our data. Despite the fact that four items were eliminated from the UPE and EPRER factors, it is unlikely that a translational issue caused the elimination of these items, as we took careful steps to ensure that the scales in the present study were translated reliably. It is more plausible that cultural differences led to this situation: specifically, it is possible that there are some aspects of intuitive eating that are specific to Brazil such as trust in one's own body, signals of fullness and hunger, and emotions that are addressed in the other items. From this perspective, the eliminated items could be considered to be less relevant to the concept of intuitive eating among Brazilians (avoid foods high in energy, feeling bored, and coping strategies). Indeed, previous studies have suggested discrepancies between scales developed in the US and translated into Brazilian Portuguese [21, 32, 33]. Returning our attention to the other psychometric evidences, the analysis also showed evidence of factorial and discriminant validity and reliability for IES-2. We found also weak invariance of IES-2 fitted model, although we suggest that this analysis should be replicated in other samples to support the suitability of the instrument for use in women and men. In relation to non-fit of the second-order factor structure, this can be attributed to the characteristics of our sample and, therefore, we suggest future studies investigate in different samples this model.

With regards to our nomological analyses, we found significant correlations among BV scores and all four IES-2 factors for both sexes, with the exception of the BFCC factor in the female sample and the UPE factor in the male sample. These results are consistent with the findings of Avalos and Tylka [34] and Tylka and Kroon van Diest [10]. Besides the fact that these results provide confirmation of our hypothesis, they also points to some proximity between body valorisation and the connection with the body, giving value for the experiences and honouring the body's needs [34]. As we develop our internal connection with ourselves, more attention is given to our possibilities and limitations, expanding consciousness and hence, developing body image.
Body care, on its turn, was correlated with all IES-2 factors on male sample and EPRER, RHSC and BFCC factors for female sample. This evidence highlights the fact that taking care of our body is associated with being aware of our internal cues of hunger and satiety. BMI correlated with RCM, $\mathrm{BV}, \mathrm{BC}$ and RHCS for males and RCM, RHSC, BFCC, BV and $\mathrm{BC}$ factors for women. It is worth noting that previous findings also showed negative and/or weak correlations [7, 8, 35]. These results indicate that caregiver and intuitive eating are weakly associated with BMI and, hence, it may not be justified to repress or control intuitive eating to control body weight. Moreover, according Schoenefeld and Webb [35] the intuitive eating could be viewed as acting in accordance with individuals' values even amidst experiencing negative feelings or thoughts about body image. The sex differences found in EPRER, RHSC and BFCC scores showed that men more likely to eat for physical rather than emotional reasons and choose their food in concordance with body need and to eat for physiological hunger than women. Perhaps, Brazilian women experience greater pressure than men to ignore aspects of food choice, since they are culturally pressured to be slim and fit-more than men - to attain standards of beauty.

This work presents some limitations. An important limitation is the fact that we were reliant on a scale developed for use, initially at least, in US English-speaking populations. Had we purposively designed items using standard scale-development procedures [36], it is possible that we might have uncovered additional content related to caregiver eating messages that are specific to Brazil. Pressure to eat to avoid wastage may be one of such issues [37] and would be worth examining in greater detail in future work. Sample characteristics (non-probabilistic sample recruitment, predominance of Caucasians, and mostly well educated) also limited the extent to which our results can be generalised to the wider Brazil population. Thus, we suggest future work in this area with larger and more diverse samples to compare with our results. Another limitation of our study that must be highlighted concerned participants' self-reported weight and height, which were used to calculate BMI. Using objectively measured indices of height and weight may be a useful way of advancing the present research. Another way in which the present work could be built on is through the use of the CEMS and IES-2 in clinical samples to assess whether the factorial structures found in the present study are consistent in clinical samples.

In conclusion, the availability of the Brazilian Portuguese versions of the CEMS and IES-2 adds to the toolbox of scholars wishing to examine the connection between eating messages and body image among Brazilian samples. Moreover, the present study provides evidence for the psychometric properties of Brazilian Portuguese versions of the CEMS and IES-2 which are important to ensure the 
quality of results when using the scale in practice as well as for comparison with other future studies. We hope that the availability of these scales will allow for more systematic investigations of eating behaviours and their association and impact on body image. More broadly, the availability of these scales raises the possibility of conducting systematic cross-cultural research that includes a nation known for its 'cult of the body'.

\section{Compliance with ethical standards}

Conflict of interest The authors declare that they have no conflict of interest.

Ethics approval Ethics approval was obtained from Human Research Ethics Committee of University of Campinas, in São Paulo, Brazil (protocol number: 08009212.9.0000.5404).

Informed consent All participants completed a free and informed consent form that was sent to the ethics committee.

\section{References}

1. Di Cesare M, Khang YH, Asaria P, Blakely T, Cowan MJ, Farzadfar F, Guerrero R, Ikeda N, Kyobutungi C, Msyamboza KP, Oum S, Lynch JW, Marmot MG, Ezzati M, Lancet NCDAG (2013) Inequalities in non-communicable diseases and effective responses. Lancet 381(9866):585-597. https://doi.org/10.1016/ S0140-6736(12)61851-0

2. WHO (2015) Healty diet. http://www.who.int/mediacentre/facts heets/fs394/en/. Accessed 20 July 2018

3. Kothe EJ, Mullan BA, Butow P (2012) Promoting fruit and vegetable consumption. Testing an intervention based on the theory of planned behaviour. Appetite 58(3):997-1004. https://doi. org/10.1016/j.appet.2012.02.012

4. Monteiro CA, Conde WL, Lu B, Popkin BM (2004) Obesity and inequities in health in the developing world. Int $\mathrm{J}$ Obes 28(9):1181-1186. https://doi.org/10.1038/sj.ijo.0802716

5. Sobal J, Wansink B (2007) Kitchenscapes, tablescapes, platescapes, and foodscapes. Environ Behav 39(1):124-421. https://doi. org/10.1177/001396506295574

6. Higgs S, Thomas J (2016) Social influences on eating. Curr Opin Behav Sci 9(1):1-6. https://doi.org/10.1016/j.cobeha.2015.10.005

7. Tylka TL (2006) Development and psychometric evaluation of a measure of intuitive eating. J Couns Psychol 53(2):226-240. https ://doi.org/10.1037/0022-0167.53.2.226

8. Kroon van Diest AM, Tylka TL (2010) The Caregiver Eating Messages Scale: development and psychometric investigation. Body Image 7(4):317-326. https://doi.org/10.1016/j.bodyi m.2010.06.002

9. Tribole E, Resch E (1995) Intuitive eating: a revolutionary program that works. St. Martin's Press, New York

10. Tylka TL, Kroon van Diest AM (2013) The Intuitive Eating Scale-2: item refinement and psychometric evaluation with college women and men. J Couns Psychol 60(1):137-153. https://doi. org/10.1037/a0030893

11. Kato M, Raposo E (1996) European and Portuguese word choice order: questions, focus, and topic construction. In: Parodi C, Quicoli C, Saltarelli M, Zubizaretta ML (eds) Aspects of romance linguistics: selected papers from the LSRL XXVI. Georgetown University Press, Georgetown
12. Imai CM, Burnett DJ, Dwyer JT (2009) The influence of culture and customs on food choices. In: Pond WG, Nichols BL, Brown DL (eds) Adequate food for all: culture, science, and technology of food in the twenty-first century. CRC Press/Taylor and Francis, Boca Raton, pp 44-66

13. Montanari M (2004) Food is culture. Columbia University Press, New York.

14. Wilk RR (1999) "Real Belizean food": building local identity in the transnational Caribbean. Am Anthropol 101(2):244-255. https ://doi.org/10.1525/aa.1999.101.2.244

15. Casotti L (2005) He who eats alone will die alone? An exploratory study of the meanings of the food of celebration. Lat Am Bus Rev 6(4):69-84. https://doi.org/10.1300/J140v06n04_04

16. Levy-Costa RB, Sichieri R, Pontes NS, Monteiro CA (2005) Household food availability in Brazil: distribution and trends (1974-2003). Rev Saúde Públ 39(4):530-540. https://doi. org/10.1590/S0034-89102005000400003

17. Malta DC, Andrade SC, Claro RM, Bernal RTI, Monteiro CA (2014) Trends in prevalence of overweight and obesity in adults in 26 Brazilian state capitals and the Federal District from 2006 to 2012. Rev Bras Epidemiol 17(1):267-276. https://doi. org/10.1590/1809-4503201400050021

18. Alvarenga MdS, Scagliusi FB, Philippi ST (2012) Comparação das atitudes alimentares entre universitárias das cinco regiões brasileiras. Cien Saude Colet 17(2):435-444. https://doi.org/10.1590/ S1413-81232012000200016

19. Hair JF, Black WC, Babin B, Anderson RE (2009) Multivariate data analysis, vol 7. Pearson Prentice Hall, New York

20. Avalos LC, Tylka TL, Wood-Barcalow N (2005) The Body Appreciation Scale: development and psychometric evaluation. Body Image 2(3):285-297. https://doi.org/10.1016/j.bodyi m.2005.06.002

21. Swami V, Campana ANNB, Fereirra L, Barrett S, Harris AS, Tavares MCGCF (2011) The Acceptance of Cosmetic Surgery Scale: initial examination of its factor structure and correlates among Brazilian adults. Body Image 8(1):179-185. https://doi. org/10.1016/j.bodyim.2011.01.001

22. Swami V (2017) Considering positive body image through the lens of culture and minority social identities. In: Markey C, Daniels E, Gillen M (eds) The body positive: understanding and improving body image in science and practice. Cambridge University Press, Cambridge

23. Fereirra L, Neves AN, Tavares MCGCF (2014) Validity of body image scales for Brazilian older adults. Mot J Phys 20(4):359-373. https://doi.org/10.1590/S1980-65742014000400002

24. Beaton DE, Bombardier C, Guillemin F, Ferraz MB (2000) Guidelines for the process of cross-cultural adaptation of self-report measures. Spine 25(24):3186-3191. https://doi. org/10.1097/00007632-200012150-00014

25. Herdman M, Fox-Rushby J, Badia X (1998) A model of equivalence in the cultural adaptation of HRQol instruments: the universal approach. Qual Life Res Int J Qual Life Asp Treat 7(4):323335. https://doi.org/10.1023/A:1008846618880

26. Marôco J (2014) Análise de equações estruturais. $2^{a}$ edn. ReportNumber, Pêro Pinheiro

27. Fornell C, Larcker DF (1981) Evaluating structural equation models with unobservable variables and measurement error. J Mark Res 18(1):39-50. https://doi.org/10.2307/3151312?uid=37376 $64: \& \% 23 \times 0026 ;$ uid $=2 \& \% 23 \times 0026 ;$ uid $=4 \& \% 23 \times 0026 ;$ sid $=21103$ 223270061

28. Kaplan D (2000) Structural equation modeling: foundations and extensions. Sage Publications, Thousand Oaks

29. Schaufeli BW, Martínez IM, Pinto AM, Salanova M, Bakker AB (2002) Burnout and engagement in university students-a crossnational study. J Cross Cult Psychol 33(5):464-481. https://doi. org/10.1177/0022022102033005003 
30. Campana ANNB, Tavares MCGCF, Swami V, Silva D (2013) An examination of the psychometric properties of Brazilian Portuguese translations of the drive for muscularity scale, the Swansea Muscularity Attitudes Questionnaire, and the Masculine Body Ideal Distress Scale. Psychol Men Masc 14(4):376-388. https:// doi.org/10.1037/a0030087

31. Birch LL, Fisher JO, Davison KK (2003) Learning to overeat: maternal use of restrictive feeding practices promotes girls' eating in the absence of hunger. Am J Clin Nutr 78(5):215-220

32. Campana ANNB, Tavares MCGCF, Silva DD, Diogo MJD (2009) Translation and validation of the Body Image Avoidance Questionnaire (BIAQ) for the Portuguese language in Brazil. Behav Res Methods 41(1):236-243. https://doi.org/10.3758/ BRM.41.1.236
33. Gouveia VV, Singelis TM, Coelho JA (2002) Self-construal scale: corroborations of its factorial structure. Aval Psicol 1(1):49-59

34. Avalos LC, Tylka TL (2006) Exploring a model of intuitive eating with college women. J Couns Psychol 53(4):486-497. https://doi. org/10.1037/0022-0167.53.4.486

35. Schoenefeld SJ, Webb JB (2013) Self-compassion and intuitive eating in college women: examining the contributions of distress tolerance and body image acceptance and action. Eat Behav 14(4):493-496. https://doi.org/10.1016/j.eatbeh.2013.09.001

36. Spector PE (1992) Summated rating scale construction: an introduction. Sage, Newbury Park

37. Bleil SI (1998) O padrão alimentar ocidental: considerações sobre a mudança de hábitos no Brasil. Cad Debate 7:2-25 